DedikasiMU (Journal of Community Service)

Volume 2, Nomor 3, September 2020

\title{
PEMBINAAN PEMBUATAN PUPUK GUANO BENTUK GRANULE PADA SMK MUHAMMADIYAH 1 GRESIK
}

\author{
Akhmad Wasiur Rizqi' ${ }^{1}$, Dzakiyah Widyaningrum², Mochammad Nuruddin ${ }^{3}$ \\ ${ }^{1,2,3}$ Program Studi Teknik Industri, Fakultas Teknik, Universitas Muhammadiyah Gresik \\ Email : akhmad_wasiur@umg.ac.id, dzakiyah@umg.ac.id, nuruddin@umg.ac.id
}

\begin{abstract}
ABTSRAK
Pupuk merupakan bahan utama yang sangat penting dalam menjaga ketersediaan kandungan unsur hara pada tanah. Pupuk terdiri dari dua jenis yaitu pupuk organik dan anorganik. Pupuk anorgani berupak pupuk sintetik (pupuk kimia). Penggunaan pupuk sintetik banyak dilakukan oleh masyarakat, karena proses yang mudah dan pupuk tersebut mudah diperoleh. Namun, penggunaan pupuk anorganik secara berkelanjutan akan menyebabkan tingkat kesuburan tanah menurun dan menyebabkab pencemaran lingkungan. Untuk mengantisipasi hal tersebut harus diimbangi dengan pupuk organik. Pupuk organik merupakan pupuk yang terbuat dari bahan alami seperti kotoran hewan, tumbuhan dan lain-lain. Pupuk guano adalah pupuk organik yang terbuat dari kotorab hewan. Pupuk ini merupakan pupuk terbuat dari kotoran hewan yaitu kelelawar. Pupuk ini memiliki kandungan yang sangat baik meliputi nitrogen, fosfor, dan potassium. Minimnya pengetahuan tentang pupuk organik guano, maka dilakukan suatu kegiatan pengabdian masyarakat tentang pembinaan pembuatan pupuk guano. Pembinaan pupuk guano yang dilakukan berbentuk granule (butiran). Objek pengabdian adalah siswa SMK Muhammadiyah 1 Gresik. Siswa SMK dipilih karena sebagai generasi muda untuk mengetahui tentang pupuk organik dan mempu melakukan penerapan pada pertanian. Kegiatan pada pengabdian meliputi penjelasan teori dan praktek pembuatan pupuk guano. Hasil dari kegiatan ini, para siswa mengetahui tentang pupuk organik yaitu pupuk guano dan kandungannya, para siswa juga mengetahui kandungan unsur hara tanah. Selain itu, para siswa mampu mengetahui dan mempraktikkan cara pembuatan pupuk bentuk granule.
\end{abstract}

Kata Kunci : Granule, Pupuk Anorganik, Pupuk Organik, Pupuk Guano. 


\section{DedikasiMU (Journal of Community Service)}

Volume 2, Nomor 3, September 2020

\section{PENDAHULUAN}

\section{A. Latar Belakang}

Pemupukan yang seimbang adalah syarat utama dalam keberhasilan untuk meningkatkan produktivitas tanaman. Upaya yang bisa dilakukan adalah melakukan pembuatan takaran yang tepat mengenai pupuk untuk tanaman. Pemupukan yang seimbang memberikan keuntungan yang sangat baik pada pertanian. Hal ini sangat bermanfaat bagi petani untuk meningkatkan produktivitasnya (Firmansyah, Syakir, \& Lukman, 2017).

Pupuk merupakan produk yang sangat vital bagi tanaman. Pada pupuk terdapat kandungan unsur hara yang sangat dibutuhkan untuk pertumbuhan tanaman. Pemupukan tanaman dapat dilakukan secara organik dan sintetik. Salah satu pupuk sintetik yang sering digunakan oleh masyarakat yaitu urea dan NPK. Penggunaan pupuk organik masih minim. Penggunaan pupuk sintetik secara terus-menerus dapat mengurangi tingkat kesuburan tanah dan juga mengurangi keanekaragaman hayati (Raksun, Japa, \& Mertha, 2019).

Pupuk organik memiliki keunggulana terhadap pupuk sintetik. Pengaruh pupuk organik sangat nyata terhadap pertumbuhan tanaman. Contoh tanaman jagung yang mengalami pertumbuhan pada parameter tinggi batang, diameter batang, indeks luas daun, panjang tongkol, dan bobot tongkol (Nurcahya, Herlina, \& Guritno, 2017). Pupuk organik merupakan pupuk yang berasal dari bahan alami seperti kotoran hewan, bagian tubuh hewan, tumbuhan, yang sangat baik untuk kesuburan tanah (Putra \& Ratnawati, 2019).

Contoh pupuk organik yaitu pupuk guano. Pupuk guano merupakan pupuk dari bahan alami yakni dari kotoran hewan. Semua kotoran hewan bisa digunakan untuk menjadi pupuk guano, namu kotoran hewan yang sering digunakan adalah kelelawar. Pupuk ini mengandung unsur hara yaitu N sebesar $15 \%$, P sebesar 54\%, K sebesar 1,7\%. Pupuk guano merupakan pupuk yang memiliki kandungan $\mathrm{P}$ dan merupakan pupuk yang tidak kalah dibandingkan dengan pupuk organik lainnya (Suhartono, Sholehah, \& Murdianto, 2020).

Pupuk guano yang berasal dari kotoran kelelawar telah melalui proses pengendapan di dalam gua dan telah bercampur dengan bakteri pengurai dan tanah. Pupuk ini memiliki kandungan yang sangat bagus untuk pertumbuhan. Pupuk ini mengandung nitrogen, fosfor, dan potasium (Karnilawati, Fadhli, \& Muksalmina, 2020). Pupuk guano banyak mengandung unsur hara yaitu C, N, mineral. Pupuk ini mampu meningkatkan keseuburan tanah dan memperbaiki tekstur tanah (Taofik, Setiati, \& Purnama, 2018). 


\section{DedikasiMU (Journal of Community Service)}

Volume 2, Nomor 3, September 2020

Jenis pupuk terdapat dua yaitu cair dan padat. Bentuk padat biasanya berupa butiran. Pengetahuan akan pupuk guano masih minim dikalangan masyarakat. Masyarakat masih banyak ketergantungan terhadap pupuk kimia (sintetik) seperti pupuk urea dan sebagainya. Pupuk kimia (sintetik) banyak diminiti karena mudah diperoleh dan proses penggunaannya tidak terlalu membutuhkan waktu yang lama. Namun, penggunaan secara berkelanjutan akan membuat tingkat kesuburan tanah menurun dan menyebabkan pencemaran laingkungan.

Salah satu program kegiatan yang dilakukan untuk memperkenalkan pupuk organik guano adalah kegiatan pengabdian masyarakat. Kegiatan pengabdian ini meliputi pembinaan tentang edukasi dan praktek tentang pengenalan dan pembuatan pupuk organik secara umum dan pupuk guano. Pupuk guano terdapat dua jenis bentuk yaitu granule (butiran) dan non granule. Program Studi Teknik Industri Universitas Muhammadiyah Gresik melalui dosennya melakukan suatu kegiatan pengabdian masyarakat yaitu pembinaan pembuatan pupuk guano berbentuk granule. Pengabdian dilakukan untuk memberikan edukasi, pelatihan serta pengenalan dan manfaat tentang pembuatan pupuk guano berbentuk butiran. Selain itu, hal ini memberikan informasi bahwa pupuk organik selain guano juga dapat dijadikan dalam bentuk butiran (granule).

Sasaran pengabdian internal yaitu siswa SMK yang berhubungan dengan pertanian. Pemilihan siswa SMK untuk memberikan daya tarik pada generasi muda tentang pertanian. Adanya pelatihan ini diharapkan para generasi muda mampu melakukan implementasi pada dunia pertanian dan terjun langsung pada masyarakat. Objek pengabdian internal ini adalah siswa SMK Muhammadiyah 1 Gresik.

\section{B. Tujuan Kegiatan}

Adapun tujuan kegiatan dari pengabdian adalah :

1. Memberikan edukasi mengenai industri pertanian tentang pupuk baik organik dan anorganik,

2. Memberikan pengetahuan tentang kandungan unsur hara dalam tanah, dan bagaimana melakukan penyeimbangan agar tanah tetap terjaga kandungan unsur haranya.

3. Memperkenalkan tentang pupuk guano, kandungan serta bentuk dari jenis pupuk guano.

4. Melakukan kegiatan praktek pembuatan guano untuk pengetahuan dan implementasi pembauatan pupuk. 


\section{DedikasiMU (Journal of Community Service)}

Volume 2, Nomor 3, September 2020

\section{METODE PELAKSANAAN}

Adapun metode pelaksanaan tentang pengabdian internal ini sebagai berikut :

1. Pemaparan serta presentasi penjelasan mengenai pengetahun dan fungsi dari pupuk secara umum.

2. Presentasi mengenai kandungan unsur hara dalam tanah

3. Penjelasan kelebihan dan kelemahan dari pupuk baik organik maupun non organic

4. Penjelasan mengenai tentang pupuk guano.

5. Penjelasan tentang kandungan, kelebihan dan kelemahan pupuk guano

6. Praktek pembuatan pupuk guano di laboratorium.

Lokasi Kegiatan pengabdian internal pada SMK Muhammadiyah 1 Gresik di lingkungan Universitas Muhammadiyah Gresik oleh Prodi Teknik Industri akan diselenggaran di Aula Universitas Muhammadiyah Gresik dan praktek pembuatan pupuk di laboratorium proses manufaktur pada tanggal 25 Februari 2020.

Peralatan dan bahan pengabdian masyarakat di lingkungan Universitas Muhammadiyah Gresik untuk SMK Muhammdiyah 1 Gresik sebagai berikut :

- Ruangan aula untuk seminar

- laboratorium untuk praktek pembuatan pupuk

- LCD

- Laptop

- Mesin mixer camputan bahan pupuk

- Mesin pencetak butiran pupuk

- Kotoran kelelawar

- Cairan EM4

- Air

- Tempat pupuk jadi (terpal). 


\section{DedikasiMU (Journal of Community Service)}

Volume 2, Nomor 3, September 2020

\section{HASIL DAN PEMBAHASAN}

Pada hasil dan pembahasan ini menjelaskan tentan kegiatan dalam melakukan pembinaan mengenai kegiatan pengabdian internal :

\section{A. Edukasi tentang pupuk}

Proses edukasi tentang pupuk secara umum meliputi tentang pupuk organik, pupuk an organik, penjelasan tentang pupuk guano, kandungan unsur hara pada pupuk guano,dan penjelasan alat untuk pembuatan pupuk guano. Selain itu, menjelaskan akan pentingnya keseimbangan dalam mengelola pupuk pada tanaman agar unsur hara pada kandungan tanah tetap tersedian. Komposisi pupuk sebesar $40 \%$ anorganik dan $60 \%$ organik. Pada sesi ini juga melakukan tanya jawab dengan para siswa SMK Muhammadiyah 1 Gresik.

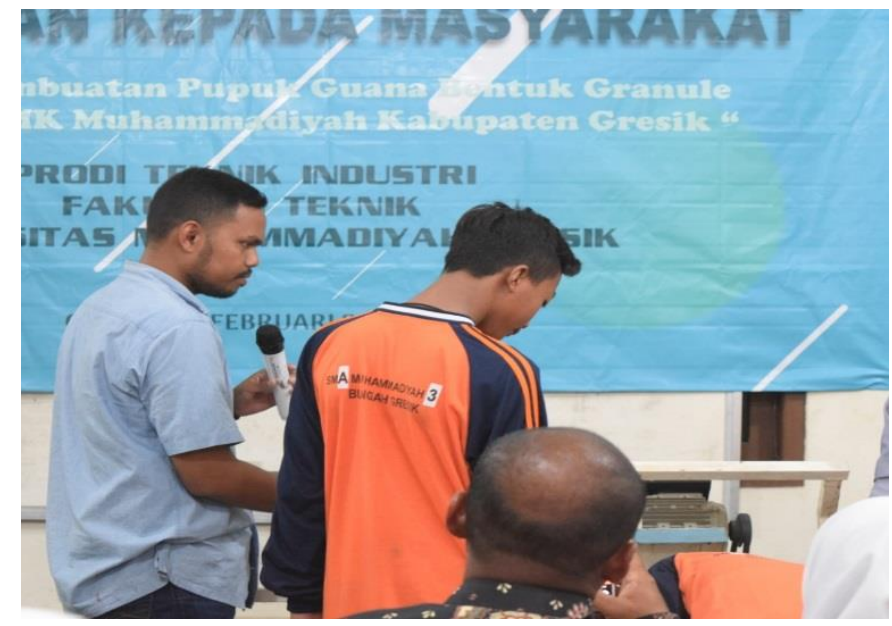

Gambar 1. Penyampaian materi

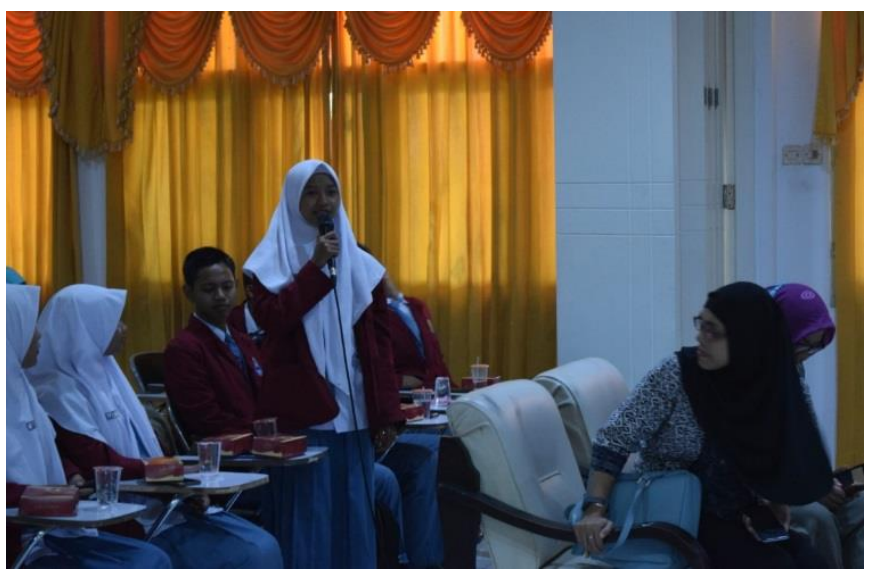

Gambar 2. Tanya jawab peserta 


\section{DedikasiMU (Journal of Community Service)}

Volume 2, Nomor 3, September 2020

\section{B. Kegiatan praktek pembuatan Pupuk}

Pada kegiatan ini melakukan praktek pembuatan pupuk guano berbentuk granule. Bahan yang digunakan meliputi air, tanah, kotoran kelelawar dan cairan EM4. Proses pembuatan guano meliputi proses pencampuran semua bahan pada mesin mixer yaitu tanah, kotoran kelelawar dan cairan EM4. Proses pengadukan dilakukan hingga semua bahan tercampur. Pemberian air dilakukan secara perlahan untuk menghasilkan butiran dari pupuk guano. Semakin banyak air maka butiran guano akan semakin tidak beraturan. Butiran yang bagus, tergantung komposisi bahan dan takaran proses perlakuan dalam prosedur pembuatan pupuk seperti pemberian air. Fungsi dari air adalah untuk merekatkan campuran dari bahan yang ada pada mesin pengadukan (mixer).

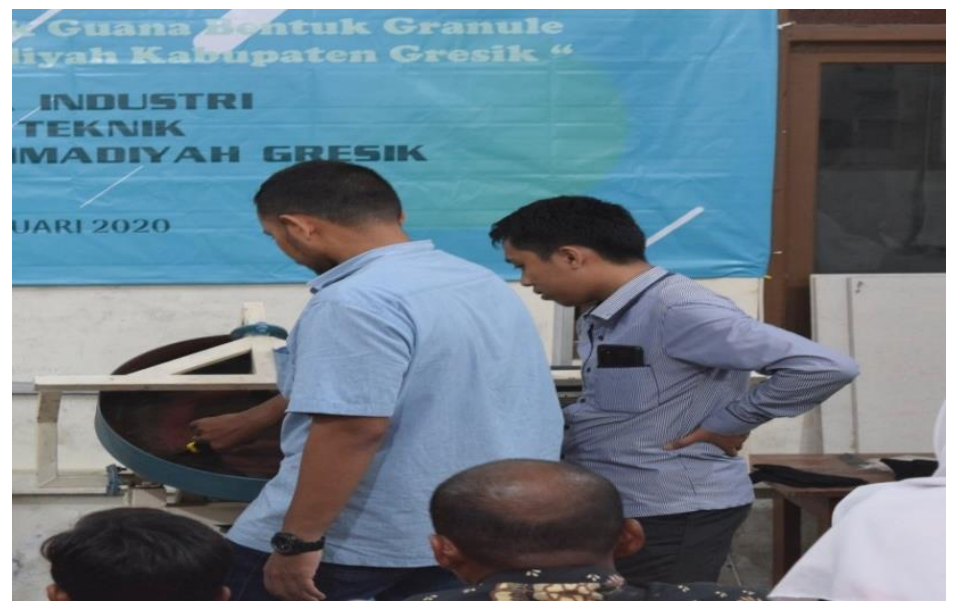

Gambar 3. Proses pengadukan dan proses pemberian air pada mesin mixer

Hasil butiran dari proses pengadukan pada mesin mixer sehingga menjadi butiran, maka dilakukan proses penyaringan untuk menyeleksi butiran pupuk guano sesuai dengan bentuk yang diinginkan. Selain itu, proses ini akan memisahkan butiran guano yang layak dan tidak layak pada tempat tertentu. Mesin penyaring berputar dengan putaran $360^{\circ}$. Berikut proses penyaringan butiran pupuk guano : 


\section{DedikasiMU (Journal of Community Service)}

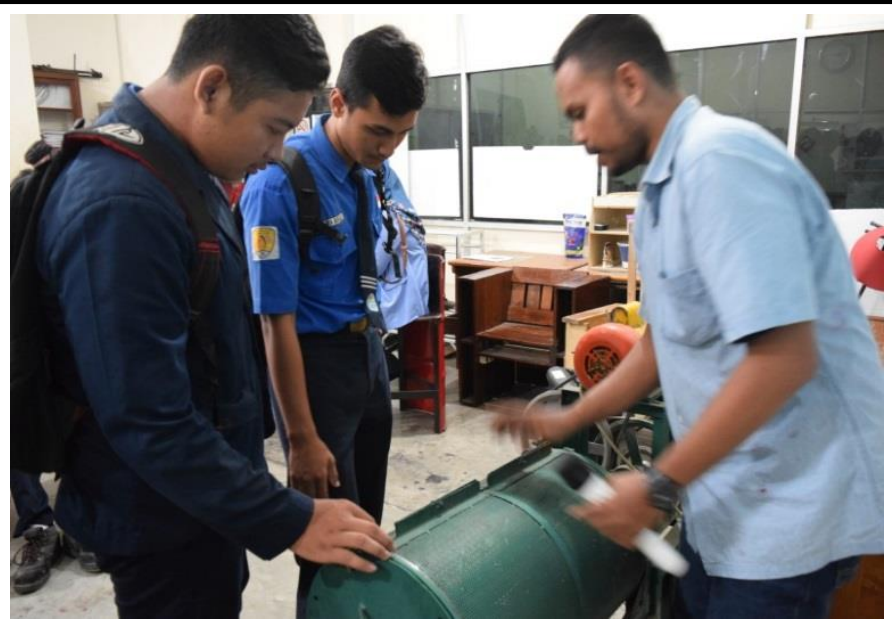

Gambar 4. Proses penyaringan butiran pupuk guano

\section{Hasil pembuatan pupuk.}

Pada kegiatan ini, merupaka hasil dari proses penyaringan dari butiran guano. Butiran guano yang sudah disaring maka dilakukan proses penjemuran. Proses penjemuran dapat dilakukan dengan sinar matahari secara terbuka. Hal ini agar butiran guano mengering, semakin kuat dan tidak mudah rusak. Proses ini bisa digunakan sebagai alternative jika ingin pupuk guano tetep berbentuk butiran. Penggunaan hasil penyaringan guano dapat langsung juga dipakai dalam pertanian khususnya sawah dan tidak pelu penjemuran.

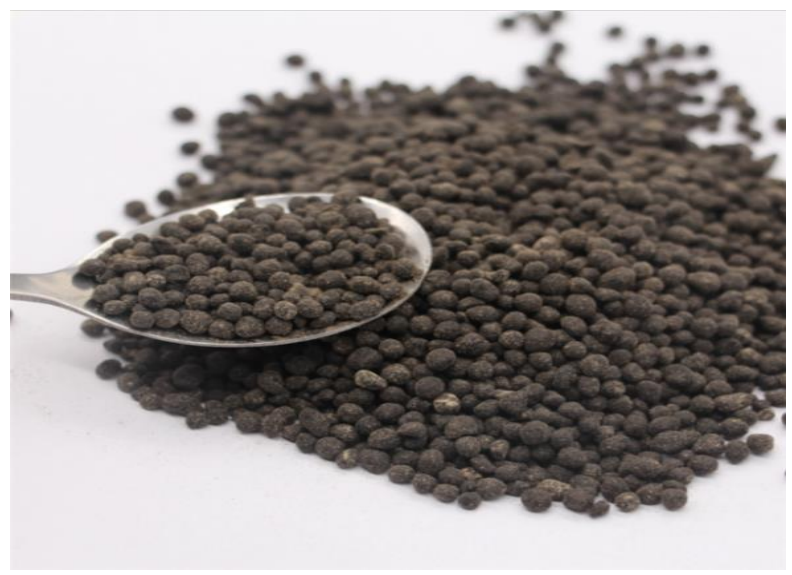

Gambar 5. Pupuk guano berbentuk granule (butiran) 


\section{DedikasiMU (Journal of Community Service)}

Volume 2, Nomor 3, September 2020

\section{KESIMPULAN DAN SARAN}

\section{A. Kesimpulan}

Berdasarkan hasil dari kegiatan pengabdian internal tentang pembinaan pembuatan pupuk guano berbentuk granule (butiran), maka para siswa mampu mengenal dan mengetahui bahwa ada pupuk organik yang memiliki kandungan yang sangat baik untuk pertumbuhan dan produksi tanaman. Para siswa juga mengerti bagaimana mengatur dan mengelola keseimbangan kandungan unsur hara pada tanah. Para siswa juga mengetahui bahwa ada altenatif bahan yang bisa digunakan sebagai pupuk organik dari kotoran hewan seperti kelelawar. Hal ini juga bisa dijadikan pupuk yang potensi dalam industri pertanian. Penambahan wawasan bahwa pupuk organic bisa diolah dalam bentuk granule (butiran).

\section{B. Saran}

Saran untuk selanjutnya, melakukan sosialisasi edukasi dan praktek untuk kalangan masyarakat luas khususnya para petani yang berhubungan langsung dengan pertanian.

\section{DAFTAR PUSTAKA}

Firmansyah, I., Syakir, M., \& Lukman, L. (2017). Pengaruh Kombinasi Dosis Pupuk N , P , dan K Terhadap Pertumbuhan dan Hasil Tanaman Terung. Hortikultura, 27(1), 69-78.

Karnilawati, Fadhli, R., \& Muksalmina. (2020). Pengaruh Pemberian Pupuk Guano Dan Pupuk Growmore Terhadap Pertumbuhan Bibit Kopi Robusta (Coffea robusta L.). Agroristek, 3(1), 13-20.

Nurcahya, A. O., Herlina, N., \& Guritno, B. (2017). Pengaruh Macam Pupuk Organik Dan Waktu Aplikasi Terhadap Pertumbuhan Dan Hasil Jagung Manis ( Zea Mays Saccharata Sturt ). Produksi Tanaman, 5(9), 1476-1482.

Putra, B. W. R. I. H., \& Ratnawati, R. (2019). Pembuatan Pupuk Organik Cair dari Limbah Buah dengan Penambahan Bioaktivator EM4. Jurnal Sains Dan Teknologi Lingkungan, 11(1), 44-56.

Raksun, A., Japa, L., \& Mertha, I. G. (2019). Aplikasi pupuk organik dan npk untuk meningkatkan pertumbuhan vegetatif melon (cucumis melo l.). Jurnal Biologi Tropis, 19(1), 19-24. https://doi.org/10.29303/jbt.v19i1.1003. 


\section{DedikasiMU (Journal of Community Service)}

Volume 2, Nomor 3, September 2020

Suhartono, Sholehah, D. N., Murdianto, R. S. (2020). Respon Pertumbuhan dan Produksi Andrographolida Tanaman Sambiloto (Andrographis paniculata Nees) Akibat Perbedaan Dosis Pupuk Guano. Rekayasa, 13(23), 164-171.

Taofik, A., Setiati, Y., \& Purnama, L. (2018). Kombinasi Guano Kelelawar Dengan Pupuk Urea Dalam Budidaya Buncis, Phaseolus vulgaris. Seminar Nasional Fakultas Pertanian Universitas Jambi, 288-296. 